Tohoku J. exp. Med., 1974, 114, 79-88

\title{
Ascending Influenza Spread in Mice by Intraperitoneal Inoculation Determined by Immunofluorescence
}

\author{
Kazunibo Tada and Nakao Ishida \\ Department of Bacteriology, Tohoku University School of \\ Medicine, Sendai
}

TADA, K. and Ishida, N. Ascending influenza spread in mice by intraperitoneal inoculation determined by immunofluorescence. Tohoku J. exp. Med., 1974, 114 (1), 79-88 _ The sequence of antigen accumulation in the lung of mice infected intraperitoneally with PR8 strain of influenza virus was pursued by means of immunofluorescent (IF) staining. Influenza infection following intraperitoneal inoculation will be characterized by the fact that only when a large inoculum of virus was injected, around $50 \%$ of mice succumbed to generalized pneumonitis 6 days after infection. In such infections, virus growth in the lung reached a maximum at 3 days following virus inoculation, and at this stage, pathological features of mouse lung were comparable to those after intranasal instillation. However, initial spread of virus in the lung was found to be different from that after intranasal inoculation. IF was detected as early as $30 \mathrm{~min}$ in reticular cells locating along the lymphsinus of parabronchial lymph nodes, and this IF diminished at $24 \mathrm{hr}$. Since then, the infection spread through alveolar sac and IF was detectable in both type $A$ and $B$ alveolar cells. Ascending mode of infection through bronchioles was then detected from $24 \mathrm{hr}$ and the intensity of IF in the epithelial cells along bronchial lining reached maximum at $120 \mathrm{hr}$.- influenza in mice; intraperitoneal inoculation; immunofluorescent staining; ascending mode of infection

Selective localization of influenza virus antigens in the lung of mice infected intranasally has been proved independently in three laboratories (Hers et al. 1962; Albrecht et al. 1963; Morizuka 1963) by using the immunofluorescent staining technique. Although the virus strains used by them are different, their results are almost concordant in that the bronchial as well as alveolar cells are the main sites of virus multiplication and that the lesions such as thickened interstitium are left free of immunofluorescence (IF). However, in contrast to that, the following two authors observed the progressive and descending mode of infection along the broncho-alveolar tree: Albrecht et al. (1963) suggested the ascending mode of spread by the cilliary movement of bronchial epithelial cells. Nayak et al. (1964) further pursued the entire period of the disease in mice intranasally infected with swine 15 virus and more clearly demonstrated the descending manner of infection, and showed that the lung consolidation follows the disappearance of infected cells from bronchi and alveoli. Thus the site of virus growth limited to the epithelial

Received for publication, August 15, 1974. 
cell lining was contrasted with the site of inflammation, i.e. interstitium pneumonitis.

When mice were infected intraperitoneally with the PR8 virus, the lung was again the main organ of virus growth (Ishida et al. 1959; Sasaki 1961), where virus titer reached that obtainable after intranasal instillation whenever a large inoculum was used. The present study aimed to pursue the growth characteristics of the virus under such conditions of experimental infection.

\section{Materials and Methods}

Mice. Three-week-old albino mice of dd strain, weighing $10 \mathrm{~g}$ in average, were obtained from the Tohoku University Farm.

Virus. The PR8 strain of influenza virus was used. It has undergone more than 600 passages in mice. The test virus was obtained as the allantoic fluid harvested $48 \mathrm{hr}$ after inoculation of 10-day-old chick embryos with diluted mouse lung suspensions. The stock fluid contained $10^{2.5} 50 \%$ egg infectious doses $\left(\mathrm{EID}_{50}\right)$ and $10^{\mathrm{a} .7}$ hemagglutinin (HA) units.

Sections and stains. The removed organs were embedded in a small foil cup with $8 \%$ gelatin solution at $-86^{\circ} \mathrm{C}$. Cryostat sections $(4 \mu)$ were fixed in cold acetone $\left(-20^{\circ} \mathrm{C}\right)$ for $30 \mathrm{~min}$, dried at room temperature, rinsed with phosphate buffered saline (PBS, 0.01 M $\mathrm{pH}$ 7.2), and overlaid with the antibody with complement followed by immunofluorescent conjugate. The complement method of immunofluorescent technique used here was already reported in detail (Hinuma et al. 1962) and this consisted first in making a $1: 32$ dilution of the antiviral serum in $5 \%$ fresh normal guinea pig serum to overlay the section. The preparation was incubated in a moist chamber for $30 \mathrm{~min}$ at $37^{\circ} \mathrm{C}$. After being washed with PBS, it was then incubated for $30 \mathrm{~min}$ at $37^{\circ} \mathrm{C}$ with the fluorescent antibody prepared against guinea pig complement, and finally washed, dried and mounted. Specificity of staining was assured through negative control tissue sections and by blocking test.

Titrations of virus infectivity for embryonated eggs. The $\operatorname{EID}_{50}$ was determined by inoculating $0.1 \mathrm{ml}$ each of serial 10 -fold dilutions of mouse lung suspension, either after or without irrigation of the whole blood, into each of four eggs. After $48 \mathrm{hr}$ of incubation at $36^{\circ} \mathrm{C}$, the allanotic fluids were tested for the presence of hemagglutinins with chicken erythrocytes. The $\mathrm{EID}_{50}$ was calculated using the method of Reed and Muench.

Double staining by hematoxylin and eosin $(H-E)$. After the photographs of IF stained preparation were taken, the same preparation was stained by $\mathrm{H}-\mathrm{E}$ and examined. At limited occasions, succinic dehydrogenase activity was examined histochemically by means of Nitro BT method (Seligman et al. 1951).

\section{Results}

\section{Clinical symptoms}

Within a few min after the intraperitoneal inoculation of virus, the mice ruffled and trembled. However, these symptoms completely subsided within $10 \mathrm{~min}$. Three to four days after infection, crepitation of the lung was heard, as in the case of intranasal infection. Some mice also showed ruffled fur, and were hunchbacked. The infective symptoms were clear with all mice on the 5th day after infection. On the 5th day, the eyes seemed to be cyanotic. On the 6th or 7th day, dyspnea and convulsion appeared and $50 \%$ of the mice died. Nasal discharge was not recognized throughout the infection. 
Lung consolidation and virus growth

The grades of consolidation are scored according to Horsfall (Ginsberg et al. 1952); $0.5-1$ on the 3rd day, 1.5-2 on the 4th, and 2.5-3.5 on the 5th (Fig. 1), whereas the virus growth assayed by means of $\mathrm{EID}_{\mathbf{5 0}}$ gave the maximum titer on the 3rd day as a rule. In some experiments, the 5th day titer was comparable to that of the 3rd day. The highest tier obtained was $10^{8.7} \mathrm{EID}_{50} / \mathrm{ml}$ with $10 \%$ lung suspensions. When the irrigation of blood stream was attempted before the resection of mouse lung to except the viraemia and the effect of irrigation was assured with benzidin test of lung suspension, the titer of lung homogenate was fairly close to that obtained without irrigation (Fig. 2).

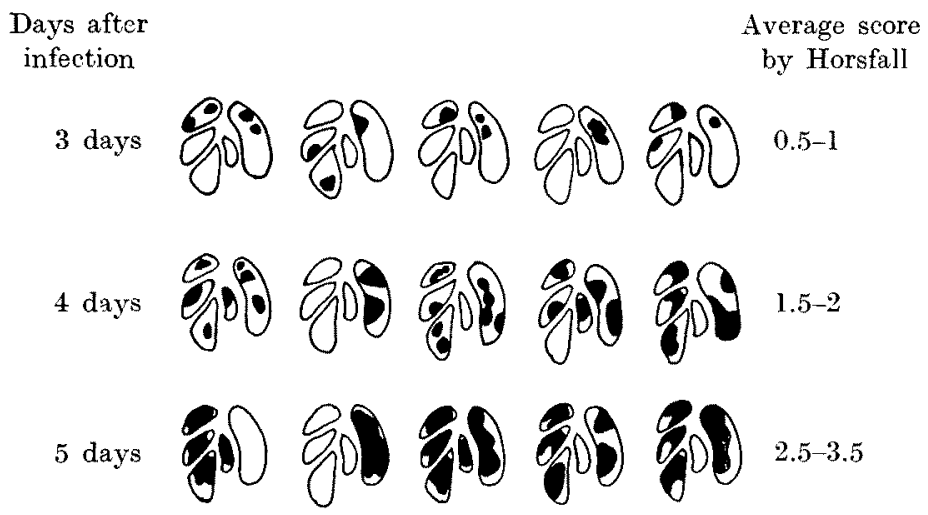

Fig. 1. Development of lung consolidation in mice infected with PR8 virus intraperitoneally.

\section{Cytological studies}

The initial histological change in $30 \mathrm{~min}$ after infection was the congestion of capillary along the alveolar wall in a fairly wide area. No other pathologic changes were recognized at this stage. Faint cytoplasmic fluorescence was found in a few of the macrophages in the septal tissue (Fig. 3), whereas all epithelial cells along the bronchial and bronchiolar lining were left free of fluorescence.

At $6 \mathrm{hr}$, the specific fluorescence was clearly detected in the cytoplasm of reticular cells locating along the lymphatic sinus of parabronchial lymph nodes (Fig. 4). Only these fluorescent reticular cells phagotized pelikan ink injected intraperitoneally together with the virus. Small lymphocytes and the cells in the lymphocytopoietic centers of these nodules were free of IF. The number of fluorescent phagocytes in the septal tissue and their IF intensity increased at 6 hr as compared with that at $30 \mathrm{~min}$. By histological examination, congestion of the capillary was still found but no migration of neutrophils. As for the cells along the bronchial and bronchiolar lining, no specific changes were observed, though some of the cells were swollen.

At $24 \mathrm{hr}$, the specific fluorescence of macrophages in the interstitial tissue 


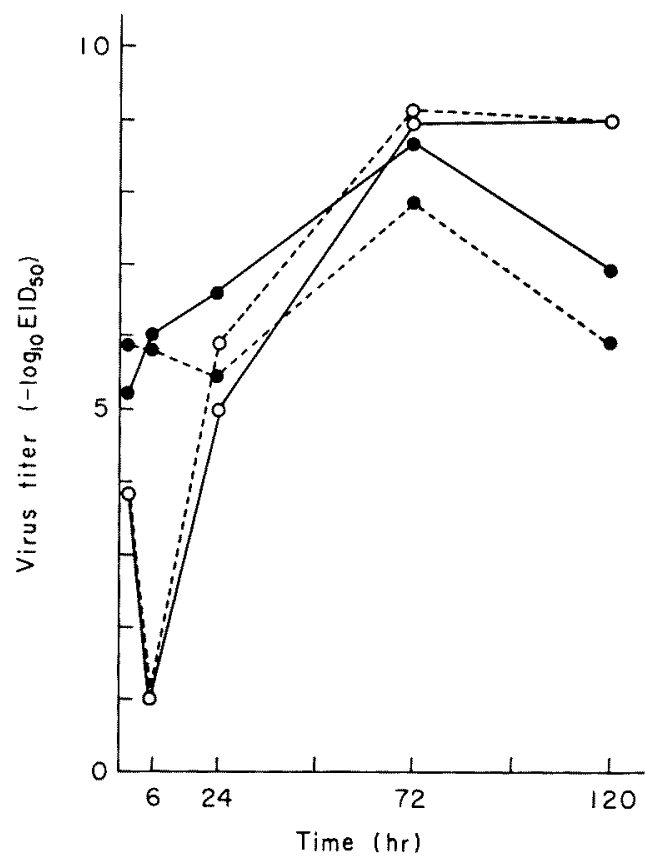

Fig. 2. Virus growth in the mouse lung infected intraperitoneally $(0)$ or intranasally (•) —-, without irrigation; - - - , with irrigation.

was found not only in the cytoplasm but also in the nucleus. This suggests the synthesis of virus within these cells. The number of these IF positive cells also increased (Fig. 5). At this stage, the alveolar cells (type A) along the alveolar wall showed faint fluorescence only in the cytoplasm. This kind of fluorescence was also detected in cytoplasm of the epithelial cells along the bronchial tree, and

Fig. 3. Faint cytoplasmic fluorescence was found in a few of the macrophages in the septal tissue, but bronchial and bronchiolar epithelial cell linings were left free of fluorescence. $30 \mathrm{~min}$ after infection. $(\times 200)$

Fig. 4. At $6 \mathrm{hr}$, the specific fluorescence was clearly detected in the cytoplasm of reticular cells locating along the lymphatic sinus of parabronchial lymph nodes. $(\times 200)$

Fig. 5. At $24 \mathrm{hr}$, the specific fluorescence of macrophages in the interstitial tissue was found not only in the cytoplasm but in the nucleus. $(\times 200)$

Fig. 6. At $24 \mathrm{hr}$, the specific fluorescence was detected in the cytoplasm of epithelial cells along the bronchial tree. $(\times 200)$

Fig. 7. At $72 \mathrm{hr}$, the alveolar macrophages protruded to the alveolar sac were stained fairly intensely, but mostly fluorescence were found in the type A alveolar cells. ( $X$ $400)$

Fig. 8. At $72 \mathrm{hr}$, in some parts of the bronchial epithelium, cells were intensely stained by IF, and the fluorescence located chiefly in the perinuclear region, but was detected also in the nucleus. $(\times 200)$

Fig. 9. At $120 \mathrm{hr}$, in the consolidated area, the specific fluorescence was detected in many phagocytes and alveolar epithel cells. $(\times 400)$

Fig. 10. At $120 \mathrm{hr}$, necrotic cells which had intense specific fluorescence both in cytoplasm and nucleus desquamated into terminal bronchial space and they partially closed the air-way. $(\times 200)$ 
the spread of virus along such cell lining was suggested (Fig. 6). The IF of reticular cells in the parabronchial lymph nodes was scarcely detected at this stage. Inflammatory changes in the lung first became apparent at this stage. They were the swelling of bronchial epithelial cells, infiltration of small round cells in the interstitial tissue, particularly along the bronchioles, and detection of erythrocytes in the alveolar space.

At $72 \mathrm{hr}$, the specific fluorescence in the reticular cells of subcapsular

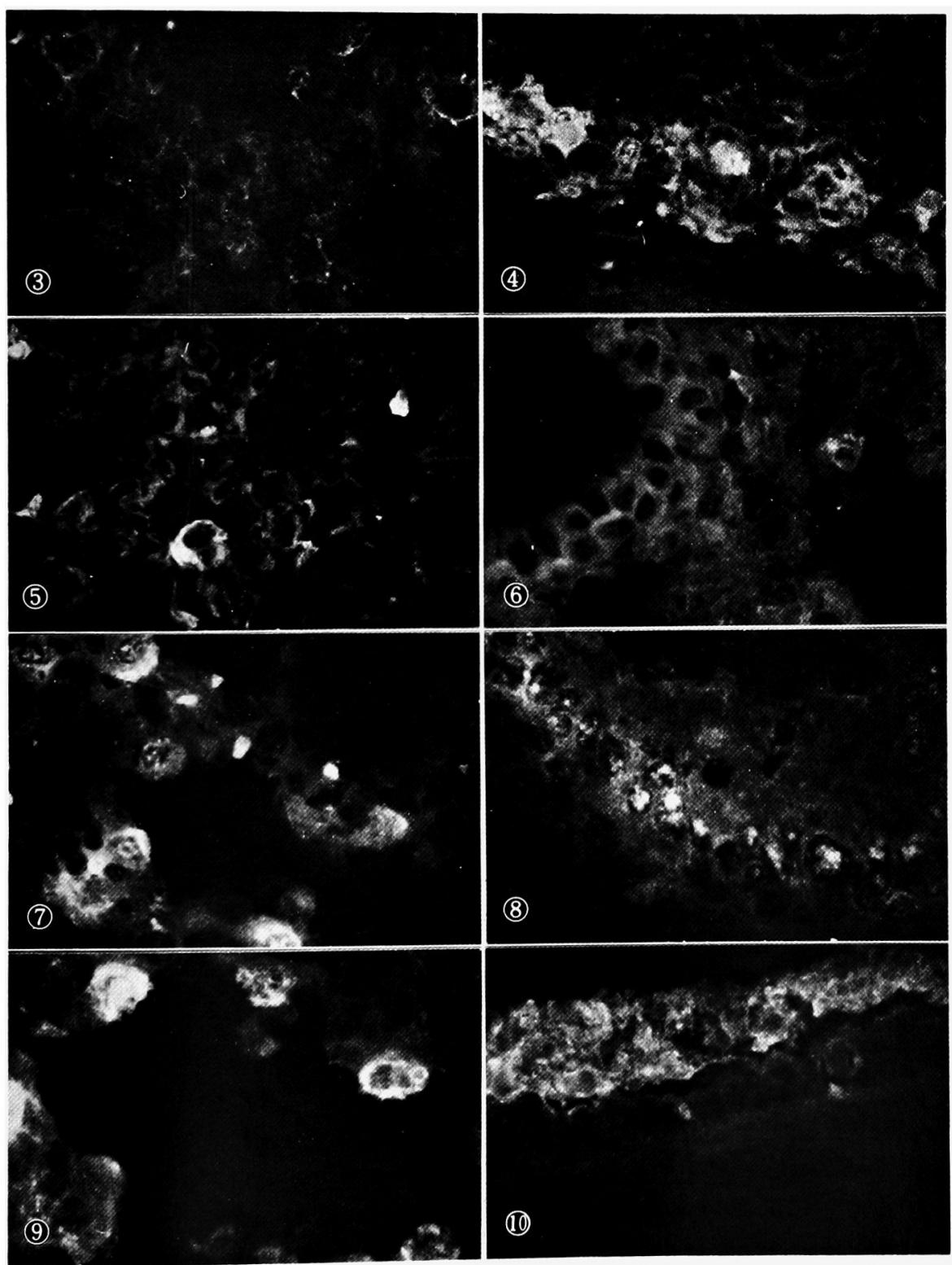



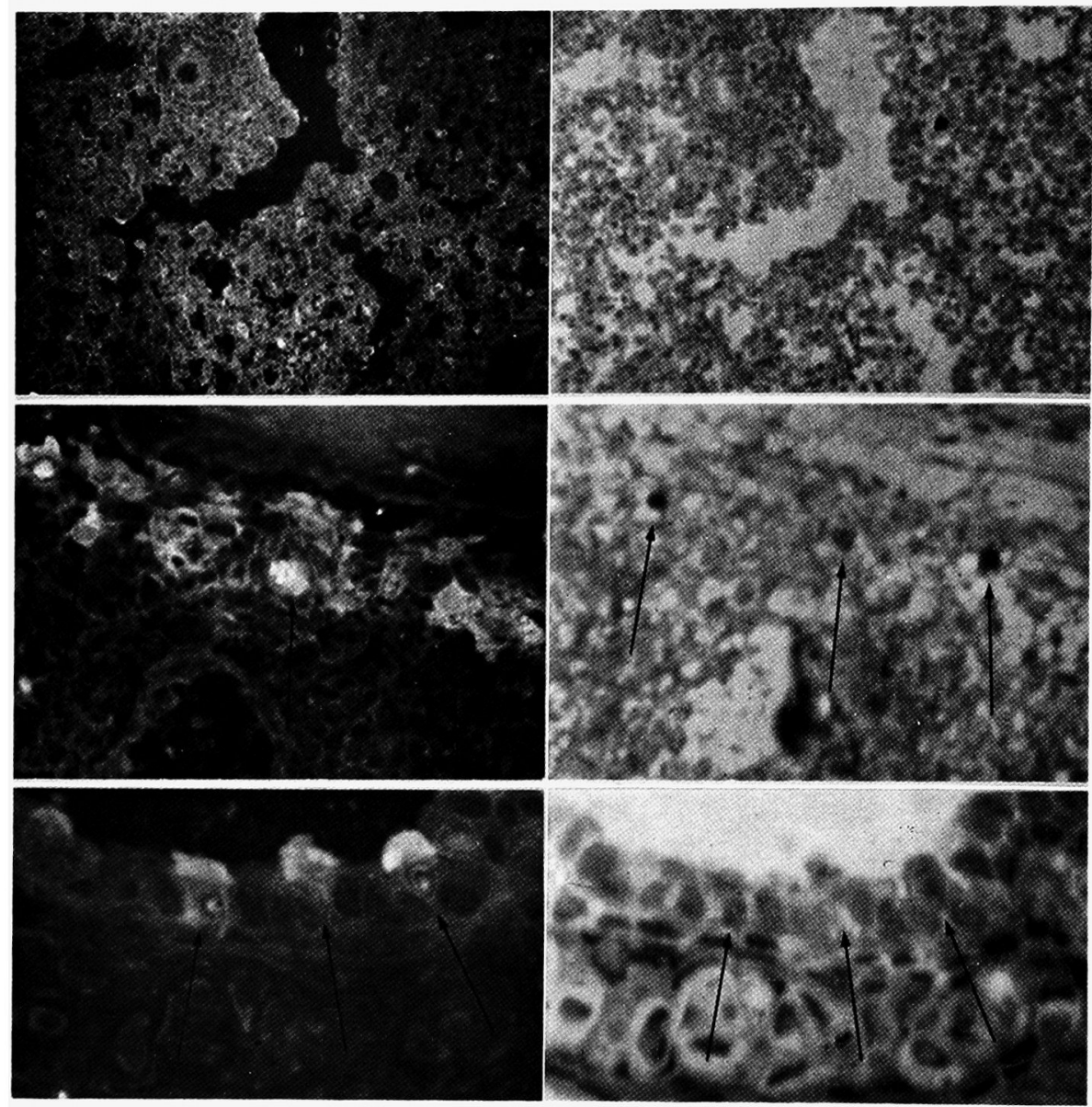

Fig. 11. Corresponding parts of bronchial epithelium stained by IF and H-E staining were compared. Each arrow shows the same cell in IF (left) and H-E staining (right). IF cells were stained eosinophilic in $\mathrm{H}-\mathrm{E}$ staining. Upper pair $(\times 100)$; middle pair $(\times 200)$; lower pair $(\times 400)$

lymphsinus was not found any more. The laveolar macrophages (type B) protruding into the alveolar sac were stained fairly intensely at this stage, and antigen accumulation in the nuclei of these cells were evident (Fig. 7). Although the differentiation of these alveolar macrophages (type B) (Yasuda 1958; Morizuka 1963) from the phagocytes, which were found in septal tissue with specific fluorescence at $24 \mathrm{hr}$, was difficult, the feature suggested that the origin of these two kinds of cells would be the same. In some parts of the bronchial epithelium, cells were intensely stained by IF, and the fluorescence was detected chiefly in the perinuclear region, and also in nucleus (Fig. 8). By means of histological examination, cell infiltration in the septal tissue became more evident, this being comparable to the feature obtained after intranasal infection.

At $120 \mathrm{hr}$, a few cells which had cytoplasmic and nuclear specific fluore- 
scence were scattered in the alveolar wall and alveolar septum. A relatively large number of phagocytes having both cytoplasmic and nuclear specific fluorescence protruded into the alveolar space. In the consolidated area, the specific fluorescence was detected in many phagocytes and alveolar epithelial cells (Fig. 9). Bronchial and bronchiolar epithelia showed intense cytoplasmic and weak nuclear specific fluorescence. In the terminal bronchial air-way, necrotic cells, which had intense specific fluorescence both in cytoplasm and nucleus, desquamated into terminal bronchial space and they partially obstructed the air-way. The newly built squamous epithelia along bronchi and bronchioles and the round cells infiltrated through the small blood vessels along bronchioles showed no specific fluorescence (Fig. 10). Virus antigens were not proved along the endothelium of blood vessels. Histologically, pathologic changes of epithelial cells of relatively large bronchi were not so severe even at this stage. However, the alveolar septa were thickened and infiltration or proliferation of mononuclear cells were most remarkable at this stage. When the cells protruding into the alveolar spaces were stained for the presence of succinic dehydrogenase activity, about a half showed positive reactions, suggesting the origination from bronchial epithelium (Hers et al. 1962). It was thus considered that the desquamated bronchial epithelium may coexist among these protruded alveolar phagocytes.

\section{Drscussion}

Virus growth in the lung of mice inoculated intraperitoneally with the PR8 strain of influenza virus is just comparable to that following intranasal infection (Ishida et al. $1959 \mathrm{a}, \mathrm{b}$ ), whereas the pathological changes of the lung following intraperitoneal infection of mice are not so severe and mortality is lower than in those infected by the intranasal route (Henle et al. 1946; Ishida et al. $1959 \mathrm{a}, \mathrm{b}$ ). In experiments conducted by Sasaki (1961) or Wagner (1956), they could not find any good explanation for such lowered mortality and pathogenicity, although their results are concordant with the above descriptions.

In this experiment, however, reasonable explanation for such observation was proposed by pursuing the time course of antigen accumulation in different cells in lung tissue.

The fact that initial detection of viral antigens was in the reticular cells of lymphsinus will indicate that a fairly large amount of inoculum virus was transported from the peritoneal cavity to the lung through the lymph flow. When Pelikan Ink was used as the counterpart of virus particles, the same flow as this reticular cells was observed, but resulted in the disappearance within $24 \mathrm{hr}$. However, possible participation of reticular cells to the viral antigen synthesis has been suggested by the detection of IF in the nuclei of these cells. These IF diminished within $24 \mathrm{hr}$ as in the case of Pelikan Ink, suggesting that these cells are not main site of virus replication but rather playing a role as scavenger cells. Mediators which played the role for the transportation of virus through such lymph flow to parenchymal tissues were macrophages in the lung. Directly via 
capillary flow or indirectly via lymph flow, these cells might be infected, and the accumulation of viral antigens in these macrophages occurred at early stage of infection, $30 \mathrm{~min}$ to $6 \mathrm{hr}$, and continued for fairly a long period.

Although there left some doubt that these macrophages participated at such initial stages are the same as phagocytic macrophages protruded into the alveolar sac and described as type $B$ alveolar cells in the text, antigen accumulation in these cells were followed by the antigen accumulation in type $\mathrm{A}$ alveolar cells (72 hr p.i.). At this second stage, i.e. when the alveolitis is occurring, IF cannot be detected through bronchial cell lining. Once the cells in the bronchial lining are infected in the third stage, however, IF features were not differentiated from those after intranasal instillation.

The amount of virus detectable in the lung following the intraperitoneal inoculation of a large dose of virus is known to be very low (Chiba 1961). This can be explained by dissemination of the inoculum to other organs, and actually it was proved by the distribution study of ${ }^{32} \mathrm{P}$-labeled virus (Ishida 1959a). Wide spread necrosis of the liver and spleen, hemorrhages into the intestine found in

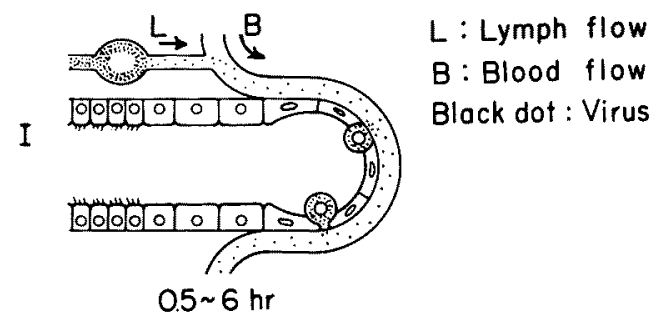

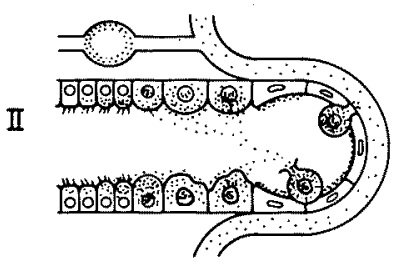

$24 \sim 72 \mathrm{hr}$

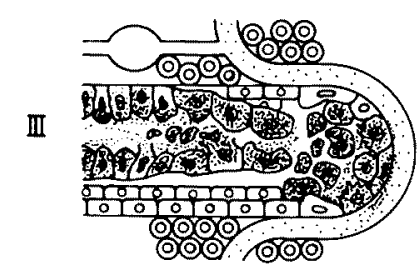

$72 \sim 120 \mathrm{hr}$

Fig. 12. Schema of virus movement and histological changes.

I) $0.5-6 \mathrm{hr}$ after intraperitoneal inoculation. Viruses penetrate the peritoneum and flow into lymph vessles. Some viruses which may pass through the lymph node flow into blood ressels while most viruses were blocked at lymph nodes. L, lymph flow; B, blood flow; black dots, virus particles.

II) At 24-72 hr. Viruses which flow into the blood vessels are phagocytosed by septal phagocytes and proliferate there in primarily. Then the infection spreads upward to bronchial epithelium secondarily.

III) At $72-120 \mathrm{hr}$. Infected bronchial epithelium and alveolar cells are destroyed and round cells without IF infiltrate around small blood vessels and bronchiolar tree. Newly formed bronchial epithilial cells have no IF. 
Henle's toxicity study (Henle et al. 1946) after intraperitoneal inoculation also support this idea. Disappearance of virus in such organs might be called the first barrier.

From the present study, the initial site where virus reaches the lung was found to be reticular cells in parabronchial lymphsinus. Probably the activity of these scavenger cells will be the second barrier to determine the further fate of virus, in the light of the fact that with 10 times diluted inoculum the antigen detection was possible only in these reticular cells.

In the next stage, one of Wagner's hypotheses (1956) that virus diffuses across the capillary alveolar membrane with reflux upward to infect adjacent epithelial cells at their respiratory surface may hold true as can be seen in the text, and it must be the determinant to allow the ascending infection. Summary of the above observation was illustrated schematically in Fig. 12.

\section{Acknowledgment}

We gratefully acknowledge the constant guidance of Prof. K. Kushima, Associate Prof. Y. Hinuma and Assistant Prof. K. Noda.

\section{References}

1) Albrecht, P., Blaskovic, D., Styk, B. \& Koller, M. (1963) Course of A2 influenza in intranasally infected mice examined by the fluorescent antibody technique. Acta Virol., 7, 405-413.

2) Chiba, A. (1961) Studies on experimental influenza in mice. VI. Production of antibody in primarily infected animals and possible effect of this antibody on the virus growth. Virus (Jap.), 11, 267-281.

3) Ginsberg, H.S. \& Horsfall, F.L.J. (1952) Quantitative aspects of the multiplication and the extend of pneumonia. J. exp. Med., 95, 135-145.

4) Henle, G. \& Henle, W. (1946) Studies on the toxicity of influenza virus. II. The effect of intraabdominal and intravenous injections of influenza virus. J. exp. Med., 84, 639-660.

5) Hers, J.F., Mulder, J., Masurel, N., Kuip, L. \& Tyrrel, D.A.J. (1962) Studies on the pathogenesis of influenza virus pneumonia in mice. J. path. Bact., 83, 207-217.

6) Hers, J.F., Willighagen, R.G., Tyrrel, D.A., Kuip, L. \& Maria, A.C. (1962) Enzyme histochemistory of bronchial epithelium and alveolar cells in the early stages of influenza virus pneumonia of mice. Nature, 193, 348-349.

7) Hinuma, Y., Ohta, R., Miyamoto, T. \& Ishida, N. (1962) Evaluation of the complement method of fluorescent antibody technique with myxoviruses. J. Immunol., 89, $19-26$.

8) Ishida, N., Kosaka, Y. and Sasaki, H. (1959a) Studies on experimental influenza in mice. III. Early distribution of $\mathrm{p}^{32}$ labelled virus in organs mice after administration from these different routes. Tohoku J. exp. Med., 71, 163-170.

9) Ishida, N., Mizuno, H., Chiba, A. \& Nakazima, S. (1959b) Studies on experimental influenza in mice. I. Virus growth and immune response in mice when the inoculum was given from three different routes. Tohoku $J$. exp. Med., 71, 137-150.

10) Morizuka, T. (1963) Studies on experimental influenza in mice. IX. Localization of virus antigen in mouse lung of influenza infection. Virus (Jap.), 13, 119-129.

11) Nayak, D.P., Kelley, G.W., Young, G.A. \& Underdahl, N.R. (1964) Progressive descending influenza infection in mice determined by immunofluorescence. Proc. Soc. exp. Biol. Med., 116, 200-206. 
12) Sasaki, Y. (1961) Studies on experimental influenza in mice. VIII. Different histopathological features of the mouse lung found between intranasal and intraperitoneal infections. Virus (Jap.), 11, 373-385.

13) Seligman, A.M. \& Rutenbery, S.H. (1951) The histochemical demonstration of succinic dehydrogenase. Science, 113, 317-320.

14) Yasuda, H. (1958) Electron-microscopic cyto-histopathology. IV. A study of normal adult and fetus lung in mammals as revealed by electron microscopy. Acta Path. Jap., 8, 189-213.

15) Wagner, R.P. (1956) Studies on the pathogenesis of influenzal pneumonitis intranasal vs. intravenous infection of mice. Yale J. Biot. Med., 28, 598-614. 